\title{
As jornalistas de desporto em Portugal: minoritárias e com pouco poder
}

\author{
Claudia Martins \& Carla Cerqueira \\ Universidade Lusófona do Porto / Universidade Lusófona do Porto, CECS \\ E-mail: cins 84 mar@gmail.com / carlaprec3@gmail.com
}

\begin{abstract}
Resumo
O mundo do jornalismo de desporto tem sido visto sença nas hierarquias das empresas mediáticas nacomo predominante e tradicionalmente masculino, cionais, concretamente nos setores dedicados à teparadigma que permanece (Strong, 2007), em que mática desportiva, continua a ser rara (Subtil, 2009). as jornalistas são consideradas outsiders pelo facto Neste artigo apresentamos os resultados de um esde serem mulheres e insiders pela sua adesão às tudo focado nas/nos jornalistas que trabalham nas normas e valores da cultura profissional (Hardin \& editorias/secções de desporto portuguesas. Através Shain, 2006: 1). Apesar de o jornalismo em Portu- de um questionário aplicado a 19 órgãos de comugal receber a entrada de mais mulheres do que ho- nicação social nacionais (i.e., agência, imprensa, rámens, podendo falar-se de uma feminização da pro- dio, televisão e online) verificamos a persistência de fissão (Subtil, 2000; Fernandes, 2008), este pano- um desequilíbrio de género, pois as jornalistas conrama não se verifica no caso do desporto, em que tinuam a ser minoritárias - $15 \%$ - e possuem pouco as mulheres enquanto profissionais continuam a sur- poder na estrutura das redações jornalísticas dedicagir em número reduzido. Paralelamente, a sua pre- das à temática desportiva $-16 \%-{ }^{1}$
\end{abstract}

Palavras-chave: jornalismo; redações; mulheres; desporto; des/igualdades de género.

\section{Women sports journalists in Portugal: a minority with few power}

\begin{abstract}
Sports journalism has been traditionally seen as a Shain, 2006). There are more women than man enmasculine ocupation. This is still a remaining pa- tering into portuguese journalism which points to a radigm (Strong, 2007). Women who work in this feminization of the profession (Fernandes, 2008). professional area are considered outsiders, precisely Despite that, this scenario is not visible when we for being women. However, as professionals, they discuss sports journalism, in which women as proare insiders because they tend to embody rules and fessionals are still outnumbered. At the same time, values of the main professional culture (Hardin \& their presence at the top management or editorial
\end{abstract}

Data de submissão: 16-08-2017. Data de aprovação: 12-03-2018.

A Revista Estudos em Comunicação é financiada por Fundos FEDER através do Programa Operacional Factores de Competitividade - COMPETE e por Fundos Nacionais através da FCT - Fundação para a Ciência e a Tecnologia no âmbito do projeto Comunicação, Filosofia e Humanidades (LabCom.IFP) UID/CCI/00661/2013.
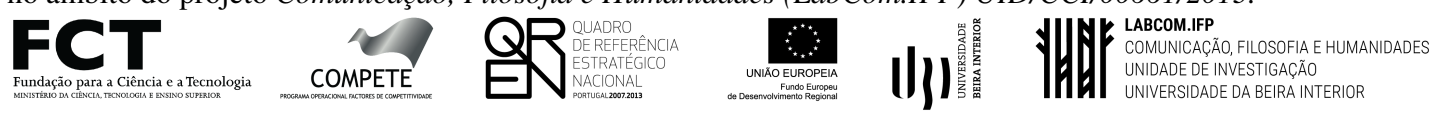

1. Não é propósito deste artigo explorar as diferenças nem proceder à demarcação entre estudos das e sobre as mulheres, que as colocam como protagonistas na história (Robinson, 1997); de género, que já abordam os papéis sociais e as representações sociais associadas ao género (Amâncio, 2001); e os estudos feministas, mais voltados para a mudança social (Silva \& Tavares, 2001). Para mais considerações a propósito destas possíveis diferenças consultar Mendes \& Carter (2008). 
coordination in national media companies, specifically in sports sections, remains rare (Subtil, 2009). In this article we present the results of a focused study about journalists who work at media sports departments in Portugal, data collected using an inquiry applied to 19 national media companies (news agency, written press, radio, television and digital). We conclude that a gender asymmetry persists, as women remain a minority $-15 \%$-, and possess few power positions in the composition of media structures $-16 \%-$.

Keywords: journalism; newsrooms; women; sport; gender equality/inequality.

\section{Introdução}

$$
\mathrm{O}
$$
JORNALISMO é, atualmente, uma profissão considerada feminizada (e.g. Marshment, 1993; Subtil, 2000, 2009; Salim, 2008; Fernandes, 2008; Ventura, 2012; Andringa, 2014). Em Portugal, os dados mais recentes nesta matéria resultam de uma análise realizada pelo Obercom Observatório da Comunicação, no âmbito do estudo "Os Jornalistas Portugueses são Bem Pagos? Inquérito às Condições Laborais dos Jornalistas em Portugal" 2 . Este último organismo indicou, em janeiro de 2017, que os/as detentores/as de Carteira Profissional de Jornalista ou de título equivalente são 6114. A amostra não-probabilística analisada no referido estudo, constituída por um total de 1494 inquiridos (validados), indica que há $51,8 \%$ de homens e $48,2 \%$ de mulheres na profissão. Comparando os dados deste inquérito com o primeiro estudo sociológico sobre a atividade jornalística em Portugal, publicado em 1988 e conduzido por Paquete de Oliveira, o crescimento nas últimas três décadas é muito evidente: em 1987 existiam 19,8\% de mulheres e $80,2 \%$ de homens no universo de jornalistas portugueses/as. Em 2008, no âmbito do projeto de investigação "Perfil Sociológico dos Jornalistas Portugueses", Isabela Salim também abordou o tema da feminização do jornalismo português e indicou a existência de 4316 homens e 3005 mulheres no universo de jornalistas portugueses, dados recolhidos através da Comissão da Carteira Profissional de Jornalista. A autora, aliás, faz uma comparação longitudinal e identifica uma evolução praticamente contínua no número de mulheres na profissão: "1987 - 19,8\%; 1990 25,4\%; 1994 - 29,2\%; 1997 - 32,8\%; 2004 - 41,4\%; 2006 - 41\%” (Salim, 2008: 117).

Contudo, "a afirmação comum de que o género é um assunto irrelevante ou menor dada a pronunciada presença de mulheres nas redações continua a ser problemática uma vez que as mulheres continuam a enfrentar discriminação sistémica de género"(Steiner, 2009: 117). A autora alertanos para a perpetuação de uma tendência que já nos anos 70 do século Xx Gaye Tuchman tinha abordado, denominando-a de "aniquilação simbólica" (Tuchman, 1978) das mulheres, referindose ao facto de o papel delas na sociedade ser, sistematicamente, trivializado e desvalorizado pelos média, quer no eixo da produção, quer da representação. A própria Tuchman, anos mais tarde, reconhece que apesar das mudanças verificadas nos média desde 1970, o problema da aniquilação simbólica persiste, limitando os horizontes das mulheres (Tuchman, 2009).

2. Inquérito desenvolvido pelo Centro de Investigação e Estudos em Sociologia (CIES-IUL) do ISCTE- Instituto Universitário de Lisboa (ISCTE-IUL) e pelo Sindicato dos Jornalistas (SJ), com o apoio da Comissão da Carteira Profissional de Jornalista (CCPJ). 
Esta evidência, aliás, mantém contornos de atualidade ao analisarmos as preocupações de sucessivos governos, instituições e organismos públicos em matéria de igualdade de género nos média. A União Europeia tem sido um dos diversos motores na consciencialização para esta questão e na tomada de medidas para a diminuir. Como prova disso mesmo surge a aprovação em Comissão do Parlamento Europeu ${ }^{3}$, em fevereiro de 2018, do relatório para a igualdade de género nos meios de comunicação social que determina a existência de quotas nos incentivos a implementar pelos Estados-membros, para que exista uma igual representação de mulheres e homens ao nível das posições de liderança nos meios de comunicação, havendo ainda recomendações no que diz respeito à promoção da igualdade salarial, à conciliação entre a vida profissional e a pessoal e ao combate ao assédio. Além das preocupações com o lado da produção de informação, sublinha-se também o outro lado, da representação das mulheres nos média, nomeadamente enquanto fontes, havendo a possibilidade de ser constituída uma base de dados de especialistas em diversas temáticas para que possa aumentar a sua presença no dia-a-dia mediático. A literacia para os média no ensino e a formação dos e das profissionais nas questões de género são outras medidas propostas pelo organismo europeu.

A entrada das mulheres num mundo maioritariamente masculino (Marques da Silva, 2010) deu-se de forma gradual, sobretudo de 1980 em diante (Subtil, 2000), o que está, em parte, relacionado com o facto de o acesso das mulheres ao Ensino Superior ter aumentado nas últimas décadas e, particularmente, aos cursos da área das Ciências da Comunicação. Ainda assim, as jornalistas portuguesas tinham pela frente uma "dupla desvantagem", pois enquadravam-se num setor atravessado "por fortes hierarquias", marcado por "questões de antiguidade" e por ser "um saber" que era "determinado pelo mundo masculino" (Marques da Silva, 2010: 309).

De acordo com Pedersen et al (2003: 390), “a masculinidade hegemónica está enraizada nos média de desporto, independentemente do sexo das pessoas que tomam decisões, escrevem notícias ou tiram fotografias", o que faz com que se perpetue e se naturalize a ideia de que os homens têm características mais vocacionadas para o desporto que as mulheres. Este artigo visa, assim, perceber se a tendência de feminização da profissão se verifica ou não no setor do desporto em Portugal.

\section{Contexto social e histórico}

É importante olharmos o presente sem ignorar os dados do passado. E por isso, nesta análise, não podemos alhear-nos do facto de Portugal ter vivido um período ditatorial de quase meio século, o que atrasou a entrada das mulheres no Ensino Superior e em determinadas áreas profissionais, como é o caso do jornalismo (Ventura, 2012), "tendo-se iniciado de forma consistente apenas no início da década de 60, mas simultaneamente progressivo e bastante pacífico" (Correia \& Baptista, 2007: 380). Foram décadas em que houve espaço para a modernidade, a inovação, o aumento dos investimentos financeiros e humanos em alguns projetos editoriais e também algum rejuvenescimento e profissionalização dos seus protagonistas (Correia \& Baptista, 2007).

3. www.europarl.europa.eu/news/en/press-room/20180219IPR98112/parliament-calls-for-measures-to-promote-g ender-equality-in-the-media-sector 
Isto refletiu-se, também, na investigação académica, pois os estudos de género surgiram, por comparação com outros países europeus, tardiamente (Amâncio, 2003). A nível internacional, estes iniciam-se por volta das décadas de 1960 e 1970, partindo de uma preocupação dos movimentos feministas relativamente às assimetrias de género existentes e ao papel dos média na (re)produção destas, nomeadamente pela estereotipização das mulheres em termos de conteúdos e pela sua ausência no eixo da produção mediática (Van Zoonen, 1994 [2009]). Fernando Correia e Carla Baptista (2007) relevam que o recrutamento de mulheres no Jornalismo em Portugal integrou uma espécie de movimento mais vasto de modificação da paisagem humana das redações e das formas de exercício da profissão, englobando fatores económicos, sociais e culturais. A entrada das mulheres no Jornalismo foi paulatina, e coberta de estranheza, sendo que algumas inicialmente estavam em salas separadas das redações (Correia \& Baptista, 2007). Há autores/as (Correia \& Baptista, 2007; Ventura, 2012) que referem um certo marialvismo que as colocava, em certa medida, como corpos estranhos no meio jornalístico, algo que se foi dissipando aos poucos.

Durante anos, as portas dos jornais mantiveram-se fechadas para as mulheres, sob os mais diversos argumentos: que a sua presença impediria os homens de falar livremente, expressandose na linguagem grosseira e recheada de palavrões que afamava o Jornalismo; que lhes seria difícil cumprir horários nocturnos (como fazer uma senhora chegar a casa de madrugada, depois de um 'piquete de fecho', quando não havia transportes públicos e os jornalistas não ganhavam o suficiente para comprar automóvel ou pagar táxis?); que não seriam capazes de enfrentar a dureza do trabalho, sobretudo em situação de reportagem; ou que elas próprias não gostariam de frequentar uma profissão de boémios e noctívagos, com pouco prestígio social e modestas regalias financeiras (Correia \& Baptista, 2007: 381-2).

Maria João Silveirinha sublinha que apesar de haver - muitas análises no campo dos estudos feministas dos média centradas em situações específicas e histórias particulares, é preciso investir na problematização e compreensão do papel das mulheres na construção do Jornalismo em Portugal e na formação dos quadros profissionais jornalísticos. Num artigo recente em que participa como co-autora salienta que apesar do número crescente de mulheres nas redações, elas continuam a ser vistas como outsiders pelos seus colegas: "Isto acontece porque as rotinas jornalísticas estão profundamente enraizadas numa cultura profissional centrada nos homens" (Lobo et al, 2015: 3).

O mesmo já havia identificado Liesbet van Zoonen (1998), quando relacionou o aumento das histórias de maior interesse humano nos média com o surgimento de mais mulheres nas redações. Contudo, a autora referiu-se à dualidade que isso criou nas profissionais, que ora tinham que provar serem boas jornalistas apesar de serem mulheres, ora tinham que mostrar serem mulheres reais, apesar de serem jornalistas. Louise North (2009) refere-se a esta cultura centrada no masculino, que muitas vezes não é entendida pelos próprios jornalistas, maioritariamente os que ocupam posições de poder, porque eles são a cultura e são eles próprios que determinam quem entra ou não nesse núcleo e quem tem ou não poder.

Urge, por isso, que aumentemos o conhecimento sobre o papel das mulheres na construção jornalística portuguesa e, especificamente, na temática desportiva. Apesar da equiparação numérica que se verifica nos dias de hoje, a investigação académica tem sublinhado a persistência de assimetrias de género nas redações (e.g. Gill, 2011; Subtil, 2009; Ventura, 2012, Subtil \& Silveri- 
nha, 2017), nomeadamente no que respeita aos postos hierarquicamente superiores nas empresas de informação, nos quais é raro encontrarmos mulheres, persistindo a segregação horizontal e vertical e identificando-se relações distintas em termos de género no campo do jornalismo (Subtil \& Silveirinha, 2017). São as “unspeakable inequalities", como designa Rosalind Gill (2011: 62), que se verificam no número de mulheres existentes no lado da produção de notícias, nas remunerações e nas hierarquias dos órgãos de comunicação social. Existem dados que comprovam "o papel relevante que as mulheres jornalistas vêm assumindo na construção da identidade profissional dos jornalistas portugueses" (Miranda, 2014: 62), muito em parte graças à "reconfiguração sexual das redações" que se verificou da década de 1970 em diante (Sobreira, 2003) e que fez com que esta deixasse de ser uma profissão de homens (Sobreira, 2003). A esses contributos juntam-se outros, como o rejuvenescimento da profissão e a composição sexual das formações superiores de jornalismo. Falta, no entanto, correspondência na composição sexual das estruturas diretivas dos meios (Miranda, 2014). Filipa Subtil e Maria João Silveirinha (2017) referem-se mesmo ao processo de feminização da profissão jornalística em Portugal como algo complexo e obstaculizado por diversas dificuldades, nomeadamente o crescimento generalizado dos níveis de instrução, o que, fez aumentar a mobilidade social, a promoção e o incremento das relações de equidade entre homens e mulheres. Paralelamente, as mulheres prosperaram nos seus direitos e entraram massivamente no mundo laboral, numa altura, em que o próprio panorama mediático atravessava mudanças aumento do número de efetivos, rejuvenescimento dos quadros e incremento das qualificações académicas dos seus profissionais (Subtil \& Silveirinha, 2017). As duas autoras consideram que apesar de se ter observado um "contínuo processo de feminização"(Subtil \& Silveirinha, 2017: 127) na profissão de jornalista, quando se afina a análise, destacam-se assimetrias nas condições e posições laborais de homens e mulheres, persistindo segregações horizontais e verticais, relações distintas de género e uma "inegável desigualdade" quanto à presença em cargos de responsabilidade e ao "desempenho de tarefas profissional e socialmente menos valorizadas e que exigem menos mobilidade e exposição pública, um cenário que se completa com a persistência de níveis salariais díspares" (Subtil \& Silveirinha, 2017: 128).

De Bruin (2014) aponta o facto de a designação de género só ter começado a surgir, relacionada com as redações jornalísticas, nos anos 80 e de até então as descrições se referirem sempre a homens, sem prestar grande atenção ao sexo e género dos/as profissionais. A autora, aliás, critica os interesses académicos, que durante muito tempo se arredaram de tentar entender as dinâmicas das redações e de identificar as estratégias de mudança das mesmas, dando mais atenção à inventariação das mulheres nas redações e aos dados do emprego (De Bruin, 2014). "É tempo de darmos um passo atrás e levantar algumas questões: que provas recolhemos? Como as usámos? Que suposições temos vindo a fazer? Que filtros talvez tenhamos usado? A nossa terminologia foi clara?" (De Bruin, 2014: 41). A autora evoca Gallagher (1981) para sublinhar que a partir de certa altura se tornou evidente, empiricamente, que as mulheres eram minoritárias nas redações, na gestão das empresas mediáticas e estavam sub-representadas nos postos de tomada de decisão. Contudo, a postura de "contagem de corpos" (De Bruin, 2014) apresentava limitações que a própria autora queria ultrapassar, desde logo avaliando a qualidade das relações de género e das interações na cultura das redações. "Tornou-se consensual que 'a predominância de homens na redação' permitisse que os valores masculinos e o seu juízo determinassem - e influenciassem - a 
produção profissional. Alguns autores chamaram a atenção para as normas machistas na recolha de notícias (Skidmore, 1998), outros sugeriram que o jornalismo e a feminilidade - leia-se profissionalismo e género - não encaixavam juntos ou descreviam processos subtis 'como o privilegiar, seletivamente, os discursos e as formas de conhecimento masculinos sobre os femininos' (Kitzinger, 1998: 187). Um mecanismo semelhante, mas relativo às teorias dos média, foi introduzido por Rush (2011, p.271), que se referiu às assunções implantadas no masculino como o agenda-setting ou a dependência dos média' (De Bruin, 2014: 43). A autora (2000) sugere como possibilidade, aliás, a ocorrência de uma "fusão de identidades", que se aproxima de uma identidade profissional única, mais voltada para os valores organizacionais da profissão.

Ainda que o número de mulheres que ingressam na profissão de jornalista seja crescente, as que entram nas secções de desporto são ainda escassas e esses departamentos temáticos continuam a ser predominantemente masculinos em vários países (Franks \& O’Neill, 2016). Chambers et al (2004) referem, até, que as redações de desporto personificam uma das mais intensas e historicamente prolongadas assimetrias de género no Jornalismo, o que se reflete, sobretudo nos assuntos cobertos, na forma como os e as atletas são tratados/as em termos jornalísticos e também que géneros são valorizados nas audiências.

Em termos empíricos, o Global Media Monitoring Project (GMMP) ${ }^{4}$ é o maior e mais longo estudo longitudinal que aborda os conteúdos veiculados, mas também os/as produtores/as de informação. Existe desde 1995 e realiza uma monitorização dos órgãos de comunicação social televisão, imprensa, rádio e meios digitais - de cinco em cinco anos, num dia específico. Nos 20 anos que o GMMP analisou, conclui-se que não existe igual número de mulheres e homens jornalistas nas redações. O relatório mais recente é de 2015 , tendo sido analisado um dia de notícias nos órgãos de comunicação social de 114 países do mundo (25 de março de 2015) e a principal conclusão desta análise é a de que o progresso para as mulheres nos média sofreu uma paragem. $\mathrm{Na}$ lista elaborada pelo GMMP quanto aos temas menos prováveis de serem tratados jornalisticamente por mulheres o "desporto, eventos, jogadores, instalações, treino e financiamento" está no topo.

O Inquérito Internacional de Imprensa Desportiva de $2011^{5}$, examinou 80 jornais de 22 países, analisou o sexo dos e das jornalistas que escreviam e assinavam artigos de desporto e concluiu que em 11 mil artigos, apenas 8\% eram escritos por mulheres (Horky \& Nieland, 2011).

Num estudo efetuado nos últimos anos sobre os média do Reino Unido, Deirdre O'Neill e Suzanne Franks (2016) concluíram que há ainda muito poucas mulheres jornalistas de desporto, apesar de o número ter aumentado desde as reivindicações feministas da década de 1970, e que esta temática jornalística continua a ser dominada pelo masculino em vários países a nível mundial (Hardin \& Shain, 2005).

Nos Estados Unidos da América o panorama é semelhante e apresenta pouca evolução desde a década de 1990. "Infelizmente, excetuando alguns esforços feministas no jornalismo de revistas, o padrão das notícias desportivas na nossa cultura foi e permanece o desporto masculino" (Creedon, 1994: 21). Miller \& Miller (1995) referem que apesar de as mulheres surgirem mais

4. http://whomakesthenews.org/

5. www.playthegame.org/theme-pages/the-international-sports-press-survey/ 
frequentemente nas redações de desporto, assim que aparecem nas folhas de vencimento elas são ignoradas e designam o mundo do jornalismo de desporto como sendo tradicionalmente masculino e dominado pelos homens (1995): "Apesar dos seus números crescentes, algumas mulheres ainda enfrentam bloqueios enquanto tentam fazer o seu trabalho e subir na carreira" (Miller \& Miller, 1995: 883). Onze anos depois, Raymond Boyle refere que nos Estados Unidos da América as mulheres jornalistas de desporto enfrentam "preconceito e hostilidade", ainda que existam na história do Jornalismo do país algumas mulheres proeminentes e que se assumiram como exemplos a seguir para mulheres aspirantes a jornalistas (Boyle, 2006). Também Hardin \& Shain (2006) concluíram que a maior parte dos jornais americanos tem poucas ou nenhumas mulheres jornalistas nas secções de desporto e que há muito poucas mulheres editoras de desporto.

Relativamente a Portugal, o relatório do GMMP refere que $43 \%$ dos jornalistas nacionais são mulheres e $57 \%$ são homens. Não encontramos, no entanto, dados relativamente aos temas cobertos e por isso remetemo-nos aos dados da monitorização anterior, referente a 2010. A categoria "celebridades, artes e desporto", na qual o futebol foi o tema mais noticiado, foi a que contou com menor participação de mulheres jornalistas.

Faltam, contudo, dados específicos sobre este segmento da classe profissional de jornalista em Portugal: quantas são as mulheres jornalistas de desporto no nosso país? Em que setor dos média é maior a sua presença? Quais as suas médias de idades e o seu tempo de serviço na profissão? Em que temáticas, dentro do desporto, se focam maioritariamente? Qual a sua presença nas hierarquias das secções de desporto ou nos próprios órgãos de comunicação social desportivos? É nesta linha de investigação específica que pretendemos inscrever o estudo que aqui apresentamos.

\section{Metodologia}

Perante a parca existência de dados relativamente aos e às profissionais do Jornalismo de desporto em Portugal procedemos ao levantamento da caraterização numérica através de um inquérito por questionário enviado a 21 órgãos de comunicação social nacionais, abrangendo as diferentes plataformas jornalísticas e temáticas com base nos dados de audiência média divulgados no Anuário da Comunicação, editado pela OberCom, referentes a 2014-2015: os três canais nacionais de televisão - RTP, SIC e TVI - e o único canal televisivo subordinado ao tema desporto, a SportTV; as três rádios nacionais de notícias com maiores audiências - Rádio Renascença, Antena 1 e TSF -; os sete jornais mais lidos do país - Correio da Manhã, Jornal de Notícias, Público, Diário de Notícias, Expresso, Sol e I; a Lusa, agência nacional de notícias; os três jornais diários desportivos - A Bola, O Jogo e Record; o jornal digital Observador, o mais visível nas plataformas virtuais e os dois jornais digitais sobre desporto - MaisFutebol e zerozero.pt.

Com o objetivo de quantificarmos as e os jornalistas de desporto em Portugal, procedemos à elaboração e envio de um questionário por e-mail num processo que decorreu entre junho e novembro de 2016.

Optamos, na formulação de diversos académicos (Quivy \& Campenhoudt, 1998; Ghiglione \& Matalon, 1995) pelo questionário de administração direta ou questionário autoadministrado, ou seja, no qual o preenchimento fica a cargo do sujeito respondente, usando uma plataforma online (Google Forms). No e-mail que disponibilizava aos respondentes o URL (Uniform Resource 
Locator) de acesso ao questionário, fizemos uma breve apresentação identificando os objetivos da investigação e a instituição em que a mesma está a ser desenvolvida.

Houve uma grande preocupação em elaborarmos um questionário curto, de forma a aumentar as probabilidades de sucesso na obtenção de respostas, com questões fechadas e muito direcionadas, centradas, maioritariamente, nos números em torno das redações: número de jornalistas divididos por sexo, médias de idade, número de anos na profissão e ainda número de mulheres e homens em posições hierarquicamente superiores. Realizamos os questionários de acordo com o meio de comunicação em questão e o seu âmbito - generalista ou desportivo e dentro deste com três modelos específicos: imprensa, digital e televisão, por considerarmos que há diferenças nestas organizações jornalísticas que deviam refletir-se nas questões aplicadas, nomeadamente o facto de os diários desportivos em Portugal possuírem uma série de secções temáticas que não se encontram nos outros órgãos de comunicação social que cobrem desporto, e, também, no caso das televisões, de haver uma clara diferenciação entre as funções de repórter e de apresentador/a.

Uma das limitações dos inquéritos por questionários é o facto de o sucesso da sua aplicação estar sempre sujeito à motivação, honestidade e capacidade de resposta dos sujeitos (Sheehan, 2001) e tendo isto em consideração, optamos por fazer um follow up recorrente junto dos inquiridos, de forma a aumentar o número de respostas. Não deixaram de existir condicionantes. No caso do semanário Sol e do diário I não obtivemos retorno nem resposta e por isso estes dois jornais não foram considerados no estudo. De mencionar também que vários diretores de informação dos 21 órgãos de comunicação social para os quais foram enviados os questionários não responderam, pelo que, em grande maioria, as respostas aos questionários foram fornecidas por elementos da estrutura diretiva ou colaboradores, profundos conhecedores da realidade inquirida, ora indicados pelos próprios diretores, ora contactados por nós, graças à ajuda e disponibilidade de colegas jornalistas que nos facultaram contactos. Só nos casos do Público, do Record, do MaisFutebol e do zerozero obtivemos respostas dos diretores de informação. Importa também referir que no caso do Correio da Manhã, o questionário representa quer o jornal diário, quer o canal televisivo presente no cabo, uma vez que a redação é a mesma, de acordo com as indicações do respondente via e-mail. Há também a sublinhar a ausência de algumas respostas quando foram pedidas médias (de idades, de anos na profissão). No total, responderam 19 dos 21 órgãos de comunicação social inquiridos.

\section{Resultados}

O resultado dos questionários aplicados fez-nos concluir que no total da nossa amostra, há 456 jornalistas a trabalhar em desporto no nosso país, dos quais 388 são homens (85\%) e 68 são mulheres (15\%) (cf. Tabela 1). O meio com menor presença feminina é a rádio - 3 mulheres e 28 homens -, a televisão segue-se com 15 mulheres e 73 homens e a imprensa escrita é a que possui mais mulheres, sendo também o setor que apresenta mais jornalistas: 267, 37 mulheres e 230 homens (Cf. Tabela 2). Se compararmos estes dados com aqueles que apresentamos acima referentes à análise realizada pelo Obercom - Observatório da Comunicação, no âmbito do estudo "Os Jornalistas Portugueses são Bem Pagos? Inquérito às Condições Laborais dos Jornalistas em Portugal", desenvolvido pelo Centro de Investigação e Estudos em Sociologia (CIES-IUL) do ISCTE - 
Instituto Universitário de Lisboa (ISCTE-IUL) e pelo Sindicato dos Jornalistas (SJ), percebemos a distância que existe entre as percentagens que se referem à profissão em geral - 51,8\% de homens jornalistas e 48,2\% de mulheres jornalistas - o que comprova que a feminização da profissão não se verifica quando falamos numa temática específica como é o desporto.

Os jornais Record e A Bola são os que mais mulheres têm nas suas redações - 12 -, o que não deixa de se relacionar com o facto de serem os dois órgãos com maiores redações e com maior número de homens: 75 e 60 , respetivamente.

Tabela 1. Número de jornalistas e jornalistas em cargos hierarquicamente superiores divididos por sexo em 19 redações/secções de desporto portuguesas

\begin{tabular}{|c|c|c|c|c|}
\hline OCS & $\begin{array}{c}\text { Homens } \\
\text { jornalistas na } \\
\text { secção de desporto }\end{array}$ & $\begin{array}{c}\text { Mulheres } \\
\text { jornalistas na } \\
\text { secção de desporto }\end{array}$ & $\begin{array}{c}\text { Homens em } \\
\text { posições } \\
\text { hierarquicamente } \\
\text { superiores }\end{array}$ & $\begin{array}{c}\text { Mulheres em } \\
\text { posições } \\
\text { hierarquicamente } \\
\text { superiores }\end{array}$ \\
\hline Record & 75 & 12 & 15 & 7 \\
\hline A Bola & 60 & 12 & 12 & 2 \\
\hline O Jogo & 45 & 5 & 6 & 1 \\
\hline SportTV & 30 & 5 & 5 & 0 \\
\hline Expresso & 2 & 1 & 1 & 0 \\
\hline TSF & 8 & 1 & 5 & 0 \\
\hline Antena 1 & 10 & 1 & 7 & 0 \\
\hline Rádio Renascença & 10 & 1 & 3 & 0 \\
\hline Agência Lusa & 37 & 8 & 6 & 0 \\
\hline Correio da Manhã & & & & \\
\hline (Jornal e TV) & 12 & 3 & 2 & 1 \\
\hline Diário de Notícias & 8 & 1 & 3 & 0 \\
\hline Jornal de Notícias & 16 & 2 & 3 & 0 \\
\hline Público & 12 & 1 & 2 & 0 \\
\hline SIC & 13 & 4 & 0 & 2 \\
\hline RTP & 18 & 2 & 3 & 1 \\
\hline TVI & 12 & 4 & 2 & 0 \\
\hline zerozero.pt & 6 & 2 & 1 & 0 \\
\hline MaisFutebol & 13 & 3 & 2 & 1 \\
\hline Observador & 1 & 0 & & \\
\hline SUB-TOTAL & 388 & 68 & 78 & 15 \\
\hline TOTAL & \multicolumn{2}{|c|}{456} & \multicolumn{2}{|c|}{93} \\
\hline
\end{tabular}


Tabela 2. Número de jornalistas divididos por sexo e por tipo de órgão de comunicação social

\begin{tabular}{lccc}
\hline Tipo de OCS & $\begin{array}{c}\text { Homens jornalistas na } \\
\text { secção de desporto }\end{array}$ & $\begin{array}{c}\text { Mulheres jornalistas } \\
\text { na secção de desporto }\end{array}$ & TOTAL \\
\hline Imprensa escrita & 230 & 37 & 267 \\
Rádio & 28 & 3 & 31 \\
Televisão & 73 & 15 & 88 \\
\hline TOTAL & $\mathbf{3 3 1}$ & $\mathbf{5 5}$ & $\mathbf{3 8 6}$ \\
\hline
\end{tabular}

\section{Mulheres com parca presença em cargos superiores}

As percentagens de homens e mulheres em posições de chefia ou cargos superiores nas redações portuguesas subordinadas à temática desportiva são, igualmente, baixas: $84 \%$ dos postos superiores são ocupados por homens, percentagem que corresponde a 78 profissionais, e $16 \%$ são pertencentes a mulheres, correspondentes a 15 num total de 93 postos hierarquicamente superiores. O jornal desportivo Record é o que possui mais mulheres nesses cargos: 7. A estação televisiva SIC destaca-se pelo fato de ter mulheres nos dois cargos superiores que existem no departamento de desporto. Estas percentagens comprovam, também, as assimetrias de género referidas acima no respeitante à presença de mulheres em postos de responsabilidade e decisão.

Uma das questões colocadas aos/às respondentes dos órgãos de comunicação social visava a redação on-line, se era separada da redação principal ou conjunta (exceção feita aos média digitais que foram incluídos neste inquérito). Apenas três dos média possuem redações on-line separadas: A Bola, a Antena 1 e a TVI. No caso do diário desportivo, há cinco homens e duas mulheres a trabalhar na redação on-line, aos quais se somam três homens e uma mulher na redação on-line da rádio pública, não tendo sido especificado, no entanto, se existe alguma divisão temática. A TVI frisou que apesar de a redação ser separada, não existem editorias, pelo que há uma equipa responsável pela atualização do site e não, propriamente, uma redação organizada.

\section{Mais novas e menos experientes}

No respeitante às idades das e dos jornalistas de desporto em Portugal, percebemos que em quase todos os órgãos de comunicação social eles são mais velhos, tendência que se pode explicar, desde logo, pelo facto de elas terem chegado mais tardiamente à profissão (cf. Gráfico 1). Nestes dados não estão contemplados os referentes ao jornal Público e à publicação digital Observador, uma vez que esses dados não foram fornecidos pelos/as respondentes. A média de idades dos homens que trabalham no Jornalismo de desporto no nosso país é de 38 anos, ao passo que a média de idades das mulheres é de 32,97. Esta é, aliás, uma tendência do jornalismo em geral, corroborada pelos dados mais recentes divulgados pelo OberCom (estudo referenciado acima) que colocam a idade média nesta classe profissional cifrada próxima dos 40 anos. 
Gráfico 1. Média de idades das e dos jornalistas de desporto em Portugal em 19 redações/secções de desporto

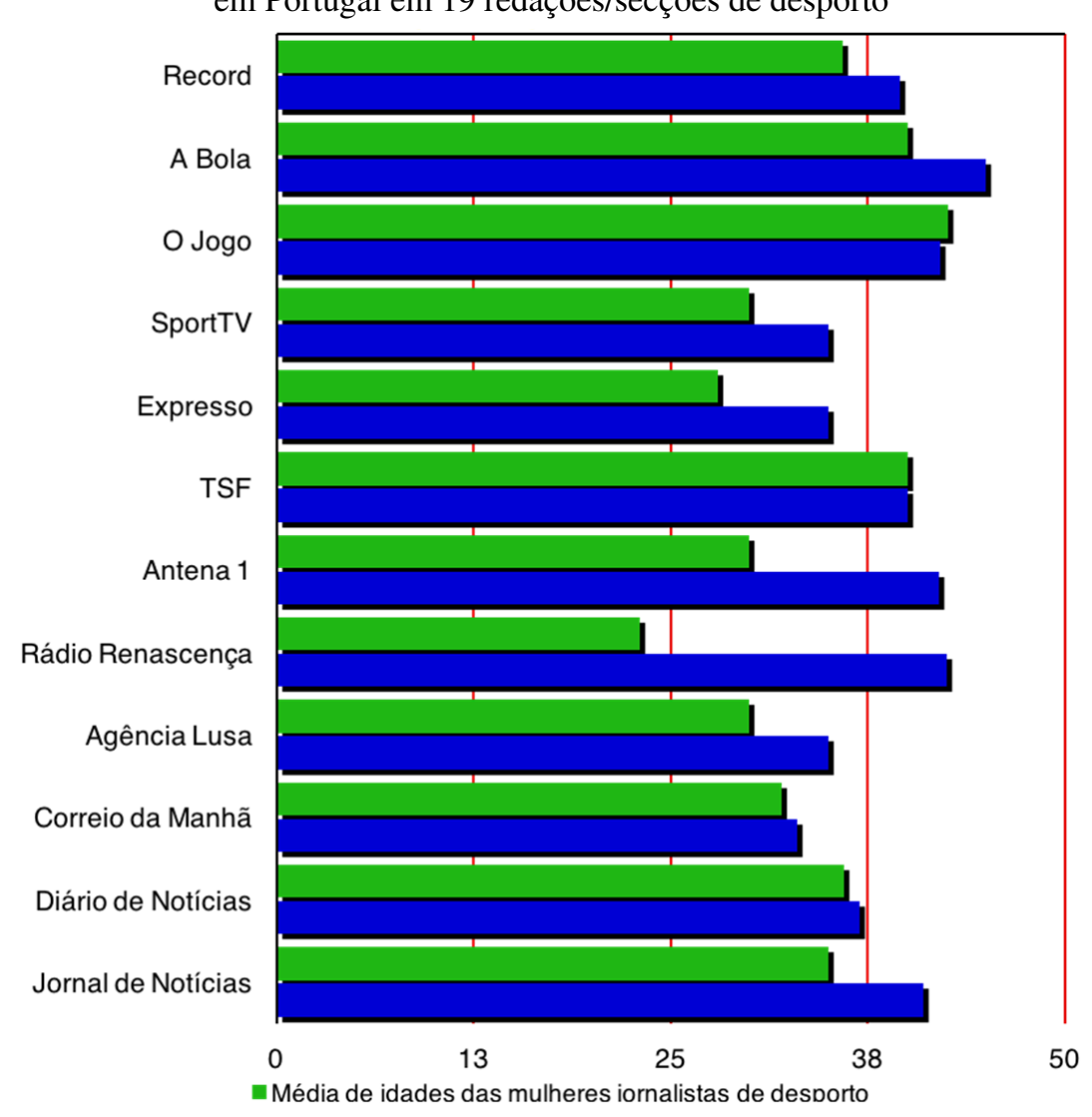

O mesmo acontece relativamente à experiência na profissão, com os homens a possuírem, em média, mais anos de prática profissional, ainda que a diferença seja menor se comparada com a média de idades - 13,54 para 10,75 (cf. Gráfico 2). Importa sublinhar que nas questões relacionadas com médias de idades ou de anos na profissão, algumas respostas dos/as inquiridos/as foram menos precisas, existindo caracterizações como 'cerca de' ou 'aproximadamente', pelo que a fiabilidade e exatidão destes dados específicos é menor. Há, também, alguns casos, em que as respostas são inexistentes em relação ao tempo de serviço (Record, SportTV e Rádio Renascença). 
Gráfico 2. Média de anos na profissão em 19 redações/secções de desporto

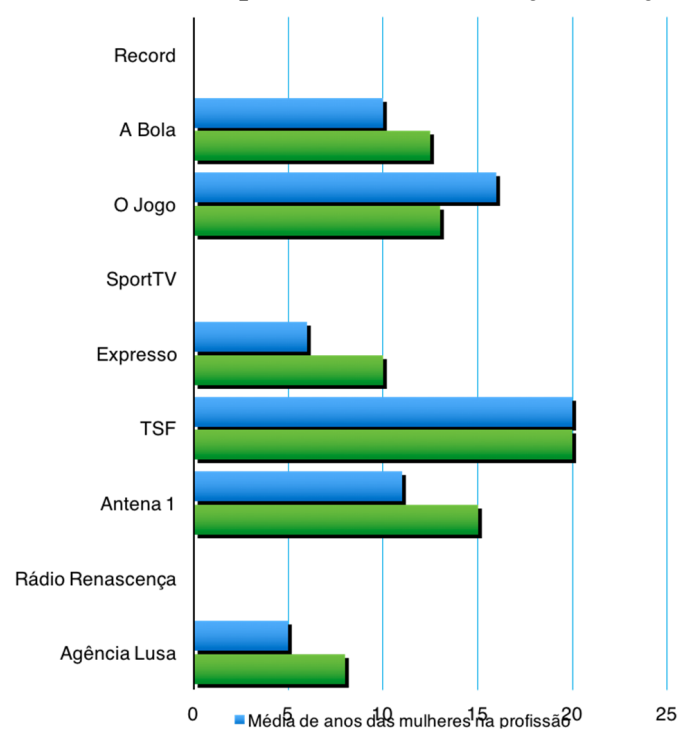

\section{Elas cobrem assuntos menos mediáticos}

Especificamente na imprensa escrita desportiva, que conta com três diários, destaca-se alguma tendência na divisão de temas dentro do desporto por mulheres e homens. Na soma dos três referidos jornais a maioria das mulheres está alocada às secções de Modalidades (10), on-line (8), Futebol Nacional (4) e Agenda (3). Os três principais clubes portugueses (Futebol Clube do Porto, Sport Lisboa e Benfica e Sporting Clube de Portugal) são alvo de maior atenção por parte da imprensa escrita e, por isso, possuem mais páginas dedicadas à sua atualidade do que os restantes clubes, modalidades ou temas. Nos três diários só há duas mulheres que trabalham nestas secções - uma na do Benfica, outra na do Sporting - e no departamento que cobre o futebol internacional não encontramos qualquer elemento feminino.

No caso do único meio televisivo em Portugal que é exclusivamente dedicado ao desporto, a SportTV, e que possui um total de 30 jornalistas, 25 homens e 5 mulheres, percebemos que duas em cinco desempenham funções de apresentação, vulgo pivot, e que as tarefas de reportagem exterior recaem sobre as 5 jornalistas da empresa. No caso dos homens, de um total de 25 , são apenas 5 os apresentadores/pivot e 15 possuem tarefas de repórter. A SportTV não tem divisão por secções temáticas, pelo que não temos dados em relação à divisão de mulheres e homens por assuntos cobertos. O mesmo acontece no que diz respeito aos dois órgãos de comunicação social digitais, MaisFutebol e zerozero.pt. 


\title{
Notas finais
}

A disparidade que encontramos entre o global (perfil numérico do/a jornalista português/esa) e o particular (perfil numérico do/a jornalista português/esa que trabalha em desporto) é grande e explica-se, em parte, através da identificação dos estereótipos de género que persistem na nossa sociedade e que vêm sendo combatidos sobretudo desde a década de 70 do século XX, bem como a rotinas jornalísticas que, de uma forma geral, são assimiladas e raramente questionadas.

\begin{abstract}
Ao discutir diferenças de género nas notícias de desporto - no que diz respeito à absoluta sub-representação das mulheres quer no conteúdo, quer na produção - os entrevistados reconheceram prontamente fortes discrepâncias de género nas estórias desportivas em jornais, revistas, programas de televisão e outros média. Contudo, nenhum jornalista expressou, explicitamente, uma visão de que isso deveria ser de outra forma e quando o tema do género e das notícias de desporto surgia, a maioria dos homens e das mulheres tendeu a minimizar ou naturalizar a tendência (Lobo et al, 2015: 8-9).
\end{abstract}

Consideramos, assim, que estes dados levantam ainda questões que são até inerentes à própria profissão de jornalista, sobretudo no campo ético do respeito pela diversidade e pela igualdade, dada a possibilidade de os papéis de género serem tipificados e incorporados na vida profissional como uma espécie de "atitude natural", na formulação de Lobo e coautoras, que não questiona a construção social (Lobo et al, 2015: 11). Afinal: "não há mudança possível sem uma renovação do imaginário coletivo. E não há renovação do imaginário coletivo se os média não representam as mudanças que vão acontecendo na sociedade" (Gallego, 2013: 11).

Considerando que os órgãos de comunicação social são, em grande medida e em muitos casos, uma representação das sociedades em que se inserem, as assimetrias de género nas secções desportivas acabam por ter repercussões nos trabalhos mediáticos, nas suas linguagens, nas suas produções jornalísticas o que, em última instância, ajuda ou retrai a mudança social, podendo contribuir para diminuir ou reforçar estereótipos, preconceitos, representações (Pissara Esteves, 1999). Tal como sustenta Gill (2013: 113-114),

as notícias são um produto cultural que reflete os pressupostos culturais dominantes sobre quem e o que é importante, determinado pela raça, género, classe, riqueza, poder e nacionalidade e sobre que relações e ligações sociais são consideradas normais, naturais e inevitáveis. Não é surpreendente, então, que a maioria das notícias sejam designadas para, sobre e por homens

Em jeito de pistas para o futuro, urge que nos foquemos, especificamente, sobre as trajetórias das mulheres que trabalham especificamente nesta área temática, perceber que barreiras encontraram e/ou encontram, com que desafios se deparam/depararam, que evolução profissional vivem/viveram. O trabalho publicado em 2015 por Paula Lobo, Maria João Silveirinha, Marisa Torres e Filipa Subtil permite-nos, desde já, perceber que apesar de as jornalistas de desporto terem consciência da existência de desigualdades de género, parecem partilhar a assunção de que o desporto é um território masculino, ainda que possuam uma posição crítica em relação à influência do género nos conteúdos editoriais. (Lobo et al, 2015) É, por isso, nosso objetivo olharmos para lá dos dados numéricos aqui apresentados e fazermos uma investigação qualitativa, junto das 
profissionais desta área temática específica. Sublinha-se, ainda, a necessidade de estabelecermos uma análise por tipo de média, percebermos o porquê de as temáticas desportivas menos mediáticas serem as mais trabalhadas por mulheres na imprensa escrita, o motivo para encontrarmos mais mulheres apresentadoras que repórteres nos canais televisivos e a explicação para a rádio continuar a ser o meio com menos profissionais mulheres neste setor.

\section{Referências Bibliográficas}

Amâncio, L. (2001). O género na psicologia: uma história de desencontros e rupturas. Psicologia, $X V(1), 9-26$.

Amâncio, L. (2003). O género nos discursos das ciências sociais. Análise Social, 38(168), 687714.

Andringa, D. (2014). Imaginário e realidade. In J. Rebelo (org.), As novas gerações de jornalistas em Portugal (pp.73-81). Lisboa: Editora Mundos Sociais.

Boyle, R. (2006). Sports journalism: context and issues. London: Sage Publications.

Cardoso, G. \& Mendonça, S. (2017). Jornalistas e condições laborais: retrato de uma profissão em transformação. [e-book]. Lisboa: OberCom. Acedido em https://obercom.pt/wpcontent/uploads/2017/03/2017_OBERCOM_Jornalistas_Condicoes_

Laborais.pdf

Cerqueira, C. (2012). Quando elas (não) são notícia: mudanças, persistências e reconfigurações na cobertura jornalística sobre o Dia Internacional da Mulher em Portugal (1975-2007). Tese de doutoramento em Ciências da Comunicação, Universidade do Minho, Braga, Portugal.

Chambers, D.; Fleming, C. \& Steiner, L. (2004). Women and journalism. London: Routledge.

Correia, F. \& Baptista, C. (2007). Jornalistas - do ofício à profissão - mudanças no jornalismo português (1956-1968). Lisboa: Editorial Caminho.

Creedon, P. J. (1994). Women, media and sport: creating and reflecting gender values. In P.J. Creedon (ed.), Women, media and sport: challenging gender values (pp. 3-27). California: Sage Publications.

de Bruin, M. (2000). Gender, organizational and professional identities in journalism. Journalism - theory, practice and criticism, 17(4), 239-260. Acedido em http://journals.sagepub.com/doi /abs/10.1177/146488490000100205.

de Bruin, M. (2014). Gender and newsroom cultures. In Media and gender: a scholarly agenda for the global alliance on media and gender [e-book]. Paris: UNESCO. Acedido em www.unesc o.org/new/fileadmin/MULTIMEDIA/HQ/CI/CI/pdf/publications/gama g_research_agenda_ bruin.pdf.

Esteves, J. P. (1999). Os media e a questão da identidade - sobre as leituras pós-modernas do fim do sujeito. Lisboa: Universidade Nova. 
Fernandes, J. L. (2008). Motivações e modos de acesso na profissão de jornalista. Trajetos, 12, 97-115.

Franks, S. \& O'Neill, D. (2016). Women reporting sport: Still a man's game?. Journalism - theory, practice and criticism, 17(4), 474-492. Acedido em http://journals.sagepub.com/doi/10. 1177/1464884914561573.

Gallagher, M. (1981). Unequal opportunities. The case of women and the media. Paris: UNESCO.

Gallagher, M. (2014). Feminist scholarship and the debates on gender and communication. In Media and gender: a scholarly agenda for the global alliance on media and gender [e-book]. Paris: UNESCO. Acedido em www.unesco.org/new/fileadmin/MULTIME DIA/HQ/CI/CI/pdf/p ublications/gamag_research_agenda_bruin.pdf.

Gallego, J. (2013). De reinas a ciudadanas. Medios de comunicación-motor o rémora para la igualdad?. Espanha: Aresta.

Ghiglione, R. \& Matalon, B. (1995). O inquérito - teoria e prática. Oeiras: Celta Editora.

Gill, R. (2011). Sexism Reloaded, or, it's Time to get Angry Again!. Feminist Media Studies, 11(01), 61-71. Acedido em http://dx.doi.org/10.1080/14680777.2011.537029.

Gill, R. (2013). Gender and the media. Cambridge: Polity Press.

Hardin, M. \& Shain, S. (2005). Female sports journalists: are we there yet? "No". Newspaper Research Journal, 26, 22-35. Acedido em www.researchgate.net/publicati on/265197297_Fema le_Sports_Journalists_Are_We_There_Yet_\%27No\% 27.

Hardin, M. \& Shain, S. (2006). Feeling much smaller than you know you are: the fragmented professional identity of female sports journalists. Critical Studies in Media Communication, 23(4), 322-338. Nova Iorque: Routledge. Acedido em www.tandfonline.com/doi/abs/10.108 0/07393180600933147? journalCode $=\mathrm{rcsm} 20$.

Horky, T. \& Nieland, U. (2011). International sport press survey 2011. Consultado em julho 27, 2017, em www.playthegame.org/fileadmin/image/PTG2011/Presentation/PTG_NielandHorky_ISPS_2011_3.10.2011_final.pdf .

Lobo, P.; Silveirinha, M. J.; Torres da Silva, M. \& Subtil, F. (2015). In Journalism we are all Men. Journalism Studies, 18(9). Acedido em www.tandfonline.com/doi /abs/10.1080/1461670X.2 015.1111161 ;journalCode $=$ rjos20.

Marques da Silva, S. (2010). Mulheres e feminilidade em culturas ocupacionais de hegemonia masculina. In V. Ferreira (org.), A igualdade de mulheres e homens no trabalho e no emprego em Portugal: políticas e circunstâncias. Lisboa: CITE.

Marshment, M. (1993). The picture in political: representation of women in contemporary popular culture. In D. Richardson \& V. Robinson (eds.), Introducing women's studies (pp. 123-150). Londres: Macmillan Press.

Mendes, K. \& Carter, C. (2008). Feminist and gender media studies: a critical overview. Sociology Compass, 2(6), 1701-1718. 
Miller, P. \& Miller, R. (1995). The invisible woman: female sports journalists in the workplace. $J$ \& MC Quarterly, 72(4), 883-889.

Miranda, J. (2014). Notas sobre o papel e a situação da mulher no processo de profissionalização do jornalismo português e no decurso da desregulação profissional. Revista Media \& Jornalismo, 25(14), 53-64.

O’Neill, D. \& Franks, S. (2016). A sporting chance for women? Gender imbalance on the sports desks of UK national newspapers. Media Report to Women, 44(1), 21-22.

Pedersen, P. M.; Whisenant, W. \& Schneider, R. G. (2003). Using a content analysis to examine the gendering of sports newspaper personnel and their coverage. Journal of Sports Management, 17, 376-393.

Quivy, R. \& Campenhoudt, L. V. (1998). Manual de investigação em ciências sociais. Lisboa: Gradiva Publicações.

Robinson, V. (1997). Introducing women's studies. In V. Robinson \& D. Richardson (eds.), Introducing women's studies: feminist theory and practice (pp.1-26). Londres: MacMillan Press.

Salim, I. (2008). A ‘Feminização’ do jornalismo em portugal. Trajetos, 12, 117-124.

Sheehan, K. B. (2001). E-mail survey response rates: a review. Journal of Computer-Mediated Communication, 6(2). Acedido em http://dx.doi.org/10.1111/j.10 83-6101.2001.tb00117.x.

Silva, A. da \& Tavares, T. (2001). Estudos culturais, estudos sobre as mulheres e estudos culturais sobre as mulheres. Ex aequo, 5, 123-148. Oeiras: Celta Editora.

Silveirinha, M. J. (2004). Os media e as mulheres: horizontes de representação, de construção e de práticas significantes. In M. J. Silveirinha (org.), As mulheres e os media (pp.5-12). Lisboa: Livros Horizonte.

Silveirinha, M. J. (2012). As mulheres e a afirmação histórica da profissão jornalística: contributos para uma não-ossificação da história do jornalismo. Comunicação e Sociedade, 21, 165-182. Braga: CECS.

Sobreira, R. (2003). Os jornalistas portugueses: 1933-1974: uma profissão em construção. Lisboa: Livros Horizonte.

Steiner, L. (2009). Gender in the newsroom. In K.W. Jorgensen \& T. Hanitzsch (eds.), Handbook of journalism studies (pp.116-29). London: Routledge.

Strong, C. (2007). Female journalists shun sports reporting: lack of opportunity versus lack of attractiveness. Communication Journal of New Zealand, He Kohinga Korero, 8(2), 7-18.

Subtil, F. (2000). As mulheres jornalistas. Biblioteca On-line de Ciências da Comunicação, 1-17. Acedido em http://www.bocc.ubi.pt/pag/subtil-filipa-mulheres-jornalistas.pdf.

Subtil, F. (2009). Anotações sobre o processo de feminização da profissão de jornalista na década de 1990. In J. L. Garcia (org.), Estudos sobre os jornalistas portugueses - metamorfoses e encruzilhadas no limiar do século XXI (pp 93-108). Lisboa: Imprensa de Ciências Sociais. 
Subtil, F. \& Silveirinha, M. J. (2017). Caminhos da feminização da profissão de jornalista em Portugal: da chegada em massa à desprofissionalização. In J. N. Matos, C. Baptista \& F. Subtil (orgs.), A crise do jornalismo em Portugal (pp. 122-133). Porto: Deriva.

Tuchman, G. (1978). Introduction: the symbolic annihilation of women by the mass media. In G. Tuchman, A. K. Daniels \& J. Benet (eds.), Hearth and home: images of women in the mass media (pp.3-38). New York: Oxford University Press.

Tuchman, G. (2009). Media, género, nichos. Revista Media \& Jornalismo, 15(8), 15-24.

Van Zoonen, L. (1994 [2009]). Feminist media studies. London: Sage.

Ventura, I. (2012). As primeiras mulheres repórteres - Portugal nos anos 60 e 70. Lisboa: Tinta da China. 